\title{
Academic Use of a Group on Facebook: Initial Findings and Perceptions
}

\author{
M.R. (Ruth) de Villiers, \\ School of Computing, University of South Africa
}

\author{
dvillmr@unisa.ac.za
}

\begin{abstract}
Social networking sites, especially Facebook, are an integral part of the lifestyle of contemporary youth. The facilities are increasingly being used by older persons as well. Usage is mainly for social purposes, but the group- and discussion facilities of Facebook hold potential for focused academic use. This paper describes and discusses a venture in which postgraduate distancelearning students joined an optional group for the purpose of discussions on academic, contentrelated topics, largely initiated by the students themselves. Learning and insight were enhanced by these discussions and the students, in their environment of distance learning, are benefiting by contact with fellow students.
\end{abstract}

Keywords: E-learning, Facebook, interaction, online discussions, social networking sites, study groups

\section{Introduction}

Facebook... The social networking site (SNS) where 'friends' meet friends, write on each other's 'walls' and renew former acquaintanceships. It is a site where users see each others' latest pictures and listen to their latest activities. Facebook was started in 2004 as a social communication tool, initially for students. For some users, it has become an addiction. After signing on and declaring one's profile, there are various forms of interaction. Most activities are purely social, such as confirming friends and communicating. Other relationships are more formal, for example, joining 'groups'. Registered Facebook users can be members of a group without being a friend of other group members. A group, like an individual member, has a Wall but, most importantly, groups are forums for discussions. Members initiate topics and, for each topic, conversations and debates ensue. The purpose of this paper is to describe and discuss the use of an academic group that was established as an optional discussion forum for students taking a postgraduate course in e-Learning in 2009 at the University of South Africa (UNISA), a distance-learning institution which is one of the world's mega-universities.

Can this powerful, pull-force tool be used meaningfully in an academic context to support true learning? Facebook's group feature is

Material published as part of this publication, either on-line or in print, is copyrighted by the Informing Science Institute. Permission to make digital or paper copy of part or all of these works for personal or classroom use is granted without fee provided that the copies are not made or distributed for profit or commercial advantage AND that copies 1) bear this notice in full and 2) give the full citation on the first page. It is permissible to abstract these works so long as credit is given. To copy in all other cases or to republish or to post on a server or to redistribute to lists requires specific permission and payment of a fee. Contact 0HPublisher@InformingScience.org to request redistribution permission. designed to support discussions on defined topics, and this paper reports on a group set up with the specific aim of supporting participative learning. By the nature and facilities of a Facebook group, it cannot serve as a system for uploads and downloads of files nor for maintenance of records; its purpose is to promote interaction and debate. These conventional functions of a learning 
management system such as uploads and downloads of academic materials, announcements, and maintenance of student records are very effectively administered on our institution's official student website, which also offers a discussion board facility. Students used this official discussion forum early in the year for queries about availability of the prescribed book, and from time to time the course leader posted announcements on it. Students were free to use this forum, but preferred to communicate with peers via the Facebook venture. The cohort who used the UNISA ELearning Study Group was a $4^{\text {th }}$-year BSc Honours group of 2009, taking a module called Concepts and Principles of e-Learning. Although it is a theoretical course, the course leader decided it should afford at least some practical exposure to online learning and, with the help of the Group administrator, the Group was established using the pre-existing structures on Facebook as a platform.

This study is being undertaken primarily to investigate whether or not such a venture can support true learning. A literature study sets the background to the use of Facebook in academic environments, after which the research methods and research questions are set out. This is followed by a description of Group events and the topics of discussion, as well as content analysis of the online discussions and thematic analysis of students' reflective essays on the Facebook venture. The paper ends with a conclusion, which re-visits the research questions.

\section{Literature Study}

\section{General Use by University Students}

Facebook (Fb) traditionally offers a social networking site (SNS) experience and, according to Lampe, Ellison and Steinfield (2008), was initially focused on college and high school networks. Facebook achieved a 'near ubiquity' on US college campuses (Lampe et al., (2008: 721) and was later expanded to workplaces. Fb has increasingly been joined by non-university users and in 2007 the profile field where users listed their 'Courses' was removed.

Describing changes in use and perceptions of $\mathrm{Fb}$ from 2006 to 2008 at a university in the USA, Lampe et al describe a variety of uses, all of them social in nature. The university users they surveyed typically visit $\mathrm{Fb}$ to maintain light-weight contact in relationships they had initially developed offline. In 2008, these users spent an average of 82 minutes per day on Fb. However 12$15 \%$ also used it in contact with university professors. There was some discomfort about university officials and future employers viewing their posted pictures, although the general perception was that non-peers such as faculty and potential employers selfdom viewed their profiles. Subsequent changes to Fb's privacy feature support controlled access to certain features, which would address concerns about faculty viewing details of their personal lives. The study found a pattern of movement from offline use on the university network to general online use. Anderson, Folkestad \& Al Doubi (2009) investigated students' perceptions of faculty use of social networking and, similarly, found that many students are uncomfortable about engaging with faculty on $\mathrm{Fb}$. Some participants felt that faculty should not be allowed on $\mathrm{Fb}$ !

Other studies investigating social networking on $\mathrm{Fb}$ by university students have been done by Madge, Meek, Wellens and Hooley (2009) and by Pempek, Yermolayeva and Calvert (2009). These studies address use by students at campuses in the UK and USA, respectively, and both report on social interaction. The latter reports on time usage, and found that the participants spent more time observing content than posting and disseminating new contributions.

Lewis, Kaufman, Gonzalez, Wimmer and Christakis (2008), developed a social network dataset based on the Facebook.com SNS, following the progress of a cohort of students longitudinally from 2006 to 2008. The study will be completed when the cohort graduates in 2009. Lewis et al point out that SN sites serve as a means of data collection and analysis. They collected data in a 
naturally-occurring environment, focusing on the social inter-relatedness of the population, as well as gender and cultural data. They found great differences in the way in which students use $\mathrm{Fb}$ for their social lives, but did not investigate academic aspects of SNSs.

\section{Academic Use of Facebook}

With the background of social use, we now focus on literature on academic-related use. In a study focused on the Facebook walls of undergraduate students in the social sciences at a UK university, Selwyn (2009) investigated why and how students communicate on Facebook in relation to their studies. He believes that SNS communication corresponds in an electronic way with face-to-face social learning contexts at academic institutions and suggests that the conversational and collaborative potential of SNSs can be tapped for academic purposes. His study points out how SNS can be used educationally to support communication between students in the same learning situations and also for educator-learner dialogue. In particular, SNSs provide channels for informal and unstructured forms of learning. On the other hand, Selwyn notes educators' concern that social networking may clash with pedagogy, that it may distract learners from their studies, and even contribute to disengaging and alienating learners. Moreover, it can have a detrimental effect on traditional skills and literacy.

Selwyn logged in regularly to sites of over 600 students, not to participate or interact, but to observe sites and profiles that were publicly accessible and to systematically archive relevant exchanges. Four percent (4\%) of postings related to studies and academic aspects of the university experience, referring to recent instances of lectures, seminars and student deliverables. The dominant roles were either the passive disengaged student or the angry, critical one. Many exchanges were critical of seminars and academic staff. Another pattern that emerged was use of $\mathrm{Fb}$ for practical information such as schedules and venues. Although this was available on official channels, some students preferred accessing $\mathrm{Fb}$ for information. Less frequently, academically-oriented exchanges occurred, relating to required reading and deliverables. This peer-topeer guidance was based on the students' personal interpretations, not on official guidance, and was sometimes inaccurate. Occasionally, there were positive occurrences, where students recommended journal articles to peers. In general, the postings were complaints, indications that these learners were disengaged from their studies, and some willful anti-intellectualism. Exchanges were pervaded with humour, including mockery of keen students. It is notable that the mature students and those who were enthusiastically intellectually engaged, did not participate, even though they were the target of certain comments.

Mazer, Murphy and Simonds (2009) investigated the impact of self-disclosure by teachers on students' perceptions of their credibility. Self-disclosure is defined according to the extent of personal information made public on an SNS by a teacher, for example, high self-disclosure involves showing pictures of one's social situations, and communicating personal preferences and relationships. Students browsed the $\mathrm{Fb}$ site of the three teachers participating in the study and found that a high level of self-disclosure made a teacher appear more credible. The study suggests that when personal information is publicised, students induce similarities between themselves and the teacher. The present researcher believes that these are sensitive issues, and that the level of personal self-disclosure by an academic is a personal decision. The issue also arises of possible manipulation to make an individual appear something he or she is not.

At present, there is a low level of use of Facebook for academic purposes in the South African academic community to which the author belongs. Cloete, de Villiers and Roodt (2009) conducted an online survey among Information and Computer Science lecturers in South Africa to ascertain their perceptions on the academic use of Facebook. Forty five questionnaires were completed. Of the 45, $25(56 \%)$ had a personal Facebook account. Of those 25, 12 (48\% of the 
account holders) had no interaction with students on Facebook, but 13 respondents ( $29 \%$ of the full sample of 45) were using Facebook in some way for interaction with students.

With relation to discussion groups, 91\% of the respondents were not affiliated with any Facebook group related to their teaching areas or research interests, and $75.6 \%$ had never used any type of online social networking for learning. Despite this, 64\% believed that Facebook could indeed be used as a tool for learning and $42 \%$ would consider using it as a means of group work or online discussions. Of those who would not use Facebook for academic purposes, the main reasons were that they felt they had better tools or that they preferred to use their institution's secure and dedicated academic site.

The literature survey did not identify any studies that describe academic use of $\mathrm{Fb}$ by using the Group facility. The researcher-cum-group facilitator acknowledges the possibility of omissions in the survey of literature, but it appears that this present study represents early research on the use of Groups for focused academic purposes. Not only is the work reported in this paper innovative in its use of an academic study group and discussion forum, but also in that it uses content analysis as a research method.

\section{Research Design and Methods, Participants, Ethical Issues}

This study describes the use of Facebook's group and discussion forum facilities for optional active participation and discussions by a post-graduate distance-learning class. As already stated, the cohort was a $4^{\text {th }}$-year BSc Honours class of 2009, doing the module, Concepts and Principles of e-Learning, referred to by the pseudonym, ELRN400. Although the course is theoretical, the author - who is the course leader - believed that it should afford at least some practical exposure to online learning. With the help of a group administrator, the UNISA E-Learning Study Group was established using Facebook's group facilities as a platform. With the venture nearing completion, the time has come to pose the initial research questions:

\section{Research Questions}

1. What was the nature of discussion content?

2. What were students' reflections on the experience?

3. Can active participation in an academic Facebook group support learning?

This is not survey research nor is it virtual observation. It is a focused study on the textual interactions and products of a dedicated group engaging in an online discussion group to support their distance-education course. Using the classification in Mouton's (2003) map of research designs, the methods used are a combination of content analysis of the discussions - mainly according to the scheme of Henri (1992); qualitative evaluation research using a simplified grounded theory approach (Glaser \& Strauss, 1967; Strauss \& Corbin, 1990); and thematic analysis to identify patterns in the textual data sets, comprising group discussions and students' reflective essays on the experience. In an iterative approach, I worked twice through the discussions on the Study Group site to select and refine the themes. Regarding the reflective studies in the ELRN400 essay assignment, I worked through them once in detail. After analyzing the essays of 10 students, saturation occurred and very few new points emerged subsequently.

\section{Participants}

In total 35 individuals joined the Group. There were three academics from the ELRN400 team: myself as course leader and sole lecturer, the group administrator, and the external marker who 
helped to assess some of the assignments. We had two academic guests. One was the dean of our faculty, herself a keen Facebooker, who joined as an interested observer. We were also privileged to have a 'guest speaker', a dean from another university, who is an expert on e-Learning. He contributed by giving students URLs of his online resources, which were valuable material for enrichment. The other 30 members were a heterogeneous group of students. Several of them disclosed their ages and work situations. At least four were over fifty and had joined Fb specifically for the group. Some were in the mid-twenties - keen 'techies' and enthusiastic Facebookers. The photos and personal anecdotes indicated that most were thirty-something professionals, many of whom already used $\mathrm{Fb}$.

The number of active members decreased due to attrition and the deliberate removal of one member. Eventually 24 members remained active, all of whom signed informed consent forms. The content of points made by participants who did not sign the informed consent document is not included in this paper (see next subsection).

\section{Ethical Issues}

Members of a Computer-Human Interaction Special Interest Group (SIGCHI) are currently investigating the research ethics for studying Web-based communities (Bos et al, 2009). The extent of online research is increasing rapidly and is extending its scope to reach cross-disciplinary communities. The report has not yet been released but its standpoints are highly relevant to research on social networks, such as this study.

Ethics of consent with regard to SNSs are a controversial issue. When interaction occurs on the public milieu of the Internet, the boundaries between public and private information are not distinct. It is not clear when participants should be asked to grant consent; whether they should be informed that research is being conducted; and whether data should be anonymous. In many situations, online social networking research cannot realistically be conducted if consent has to be obtained from every participant in the relevant online community (Bos et al, 2009). Access to users' sites raises the ethical issues of privacy, consent and confidentiality. The point could be made, as was done in Selwyn's (2009) study, that it is in ethical order to study content that constitutes 'private lives in public space' (Davies \& Marchant (2007), cited by Selwyn, 2009). The issue of access to Internet sites is contentious, but Selwyn complied with 'the (albeit contested) ethical guidelines' set out by the Association of Internet Researchers (2002, cited by Selwyn $(2009: 161))$. Features are available that Facebook members can use to block content or restrict viewers, and Selwyn restricted his study to profiles set to public viewing. He did not obtain informed consent from the students who were subjects of the study, but used pseudonyms for all the students featured, so that quotations and discussions are anonymous and confidential.

In the present situation, I encouraged the ELRN400 students to join the Group but participation was voluntary. Students were sent a letter explaining that research would be conducted on interaction patterns and themes in the group and stating that no disadvantage would accrue to students who did not participate. To ensure that all students are treated equally, a 5-mark question in the 100-mark end-of-year examination had two options - one relating to Facebook participation and the other option with alternative content for non-participants.

Ethical approaches are taken very seriously in our institution. I exercised transparency in informing my line managers about the Group and the intention to conduct associated research. Ethical clearance was obtained from the relevant institutional Ethical Clearance Committee, along with approval of the informed-consent form to be signed by participants. Following the clearance, 24 members signed consent forms, including all the active contributors. In reporting details of the discussions in this paper, there are no verbatim quotations or paraphrased reproductions of contributions from members who did not sign informed consent. 
The next section addresses the approach and content of the discussions, while the subsequent section focuses mainly on the students' reflections.

\section{The e-Learning Group and Discussion Forum}

Approximately 40 students initially registered for the module, ELRN400. Distance education is characterized by high attrition, as students discontinue for financial or workplace-related reasons, but 29 continued as serious students. Joining the Group was voluntary. As in any class, students could decide for themselves whether to engage with the study material by active conversations in any form of study group. Of the initial 35 Group members (group composition is explained under Participants in previous section), one was removed by the course leader and one removed him/herself. Of the remaining 33, 22 participated in the eight discussions in the scope of this paper, although four had low activity levels. Some of the others joined as a technicality and did not participate; some of the active members were among those who discontinued the module. Others were silent participants who followed the action with interest, but did not contribute. This section is structured under themes and patterns that characterize the discussions. It also presents content analysis based on a framework for categorizing transcripts of online asynchronous discussions.

\section{Themes and Patterns of the Discussions}

Privacy: At least two members entered via pseudonyms. In one case, I deduced this; in the other case, I gave official permission to a student whose workplace blocked access to $\mathrm{Fb}$, to register via his daughter. She was held in high regard by fellow students for 'her' discernment and depth, along with her youth and beauty. In due course, the father joined personally. His contributions replaced hers, and the issue of the attractive young member was explained. Face photographs were another sensitive point. Several members left the space for their Facepic blank; other preserved privacy by uploading babies, pets, etc. We also had an intruder from a faraway country, who joined and advertised get-rich books and courses. He started communicating with some members by personal e-email. Suspicious, a student asked him an academic question, which he could not answer. She complained to the group administrator of 'harassment' and we removed him. Another student complained about the adverts he posted. We do not know how he found our Group, which was announced only in ELRN400 study material. The course administrators take responsibility for admitting him erroneously, although in good faith. We assumed he was a bona fide student whose registration was not yet finalized.

\section{Discussion topics}

In the study material, students were told, 'It's YOUR group. Feel free to initiate discussions, new topics, do Wall writing'. They responded well. Some topics were outside the direct content of the module, such as technical issues; questions regarding another module; and discussions on terms not addressed in the course (e.g. m-learning). It was of particular interest that students initiated discussions that applied syllabus topics to contemporary phenomena. For example, there were speculations of the future role of Amazon's Kindle and there was in-depth discussion on an article on the demand-driven learning model (DDLM), which was sourced by a student. The DDLM states that technology should be supported by sound pedagogical principles. This corresponds with the stance of an article prescribed as ELRN400 study material (De Villiers (2005), which points out the need for an underlying base of learning theory for e-learning applications, so that the message, not the medium, should be emphasized. Discussion was unleashed on the role of DDLM in the context of web-based learning (WBL). Since WBL itself was new to some students, there was debate on WBL as well as on the DDLM itself. 


\section{Contribution patterns}

It appears that certain users have a pattern of Facebooking in the early hours. Several postings were made after 03:00 in the morning, local time. Some small-group conversation ensued where, for example, three students discussed the concept of using $\mathrm{Fb}$ for other than socializing. Using it in a 'subject-oriented' way had come as a novel idea, a way to 'warm up the nights'. The participants experienced it in different ways. While one found the collaboration and interaction a main reason for going onto $\mathrm{Fb}$, another found that the social 'distractions' of her friends online, status updates, and latest pictures, tend to draw one away from academic pursuits.

\section{Interaction in this form of collaborative learning}

Getting directly to the main purpose of the discussions, a student started a topic 'Interaction in collaborative learning'. He made the insightful point that, although an instructor or administrator can set up a forum, the actual usage and interaction is beyond his/her control when it comes to getting contributions. While some members participate and contribute with vigour, some did not join, and others joined to observe and 'listen'. He stated that if the course leader had made it compulsory, there would have been more interaction. The point is taken. Peers in contactteaching situations can make participation mandatory and assign scores to the content and extent of participation. However, in the context of distance learning, where learners with heterogeneous ages and experience are distributed globally, it cannot be enforced. Personal circumstances can make connectivity complex or expensive. Use of Facebook is blocked in many workplaces, so some students without connectivity at home could not use it at all. With regard to general use of discussion forums, UNISA encourages discussions on its own platform but, there too, the level of usage and participation varies from one academic to another and from student to student. Although it is beneficial to join any form of study group - online or face-to-face - it is optional and up to the individual learner. The level of participation in the Facebook forum was higher than the usual level of participation in discussions at UNISA.

\section{Relationship building}

This study is about electronic contact for academic purposes and not about online social contact. However, the academic environment led to relationship building and acquaintanceship between distance learners who previously did not even know each others' names. Postings stated that the characteristic isolation of distance learners was lifted, due to contact on the group. Collaboration was perpetuated as some students communicated further via personal e-mails and some shared articles they had sourced.

\section{Research to do assignments}

Students initially tended to use popular sources, Wiki's, and keyword searches to access information. They discussed some of their findings and I advised them to source literature only from scholar.google and the rich environment of data bases provided by our university library. A longitudinal overview of the Group's discussions shows that they gravitated towards this correct approach.

\section{Content Analysis}

Henri (1992) developed a classic analytical framework for categorizing transcripts of online asynchronous discussion groups. The approach is also discussed by De Wever, Schellens, Valcke and Van Keer (2006). Henri's analytical framework is a qualitative tool for understanding the content of computer conferencing aimed at learning. It emphasizes the process of learning and is based on criteria established upfront, focusing on the learning processes as revealed by participants' messages. As such, it is an appropriate means of analyzing the messages posted on the 
discussions of the e-Learning Group. The framework comprises five dimensions: participative, social, interactive, cognitive, and metacognitive dimensions, according to which each 'unit of meaning' is analysed. The participative dimension is not based on straight quantitative message counts. Rather, messages are subdivided into statements representing 'units of meaning', which are tallied. Learning-related messages are distinguished from the others. Although discussion forums are explicitly used for the purpose of interaction, the interactive dimension has the subdimensions of initial communication, first response and subsequent contributions. The cognitive dimension relates to discussions on solving a particular problem, while metacognitive dimensions analyse messages according to the metacognitive knowledge and skills revealed, showing how learners manage their cognitive activity. In this study, we do not investigate the cognitive-, metacognitive- and social dimensions of the students' postings. Of the twenty discussion topics that occurred within the Group to date, eight are analysed in this paper according to Henri's participative and interactive aspects. To do this, messages are subdivided into statements comprising 'units of meaning'.

Tables 1 and 2 respectively present the participative and interactive dimensions of the Group discussions, modified slightly from Henri's framework. There is a separate row for each of the eight topics selected for analysis in this study.

Table 1: Analysis of units according to categories within the Participative Dimension

\begin{tabular}{|l|l|l|l|l|}
\hline Topic & $\begin{array}{l}\text { Number of } \\
\text { postings }\end{array}$ & $\begin{array}{l}\text { Number of } \\
\text { points/responses } \\
\text { within topic }\end{array}$ & $\begin{array}{l}\text { Number of } \\
\text { participants }\end{array}$ & $\begin{array}{l}\text { Number of } \\
\text { new points }\end{array}$ \\
\hline $\begin{array}{l}\text { Interaction in collaborative } \\
\text { e-learning }\end{array}$ & $\mathbf{1 0}$ & $\mathbf{2 0}$ & $\mathbf{6}$ & $\mathbf{2}$ \\
\hline Research into e-learning & $\mathbf{9}$ & $\mathbf{1 3}$ & $\mathbf{6}$ & $\mathbf{1}$ \\
\hline Definitions of e-learning & $\mathbf{1 6}$ & $\mathbf{1 8}$ & $\mathbf{1 0}$ & $\mathbf{2}$ \\
\hline $\begin{array}{l}\text { Formal education versus } \\
\text { training }\end{array}$ & $\mathbf{7}$ & $\mathbf{1 5}$ & $\mathbf{4}$ & $\mathbf{1}$ \\
\hline e-Learning 2.0 & $\mathbf{1 0}$ & $\mathbf{2 2}$ & $\mathbf{6}$ & $\mathbf{3}$ \\
\hline Research to obtain articles & $\mathbf{9}$ & $\mathbf{1 0}$ & $\mathbf{4}$ & $\mathbf{1}$ \\
\hline $\begin{array}{l}\text { Demand-driven e-Learning } \\
\text { Model and WBL }\end{array}$ & $\mathbf{6}$ & $\mathbf{8}$ & $\mathbf{5}$ & $\mathbf{1}$ \\
\hline Amazon's Kindle & $\mathbf{1 5}$ & $\mathbf{1 7}$ & $\mathbf{5}$ & $\mathbf{3}$ \\
\hline Total & $\mathbf{8 2}$ & $\mathbf{1 2 3}$ & $\mathbf{2 1}$ & $\mathbf{1 4}$ \\
\hline
\end{tabular}


Table 2: Analysis of units according to categories within the Interactive Dimension

\begin{tabular}{|c|c|c|c|c|c|}
\hline Topic & $\begin{array}{l}\text { Major points } \\
\text { made }\end{array}$ & $\begin{array}{l}\text { Direct re- } \\
\text { sponses to } \\
\text { major point }\end{array}$ & $\begin{array}{l}\text { Indirect } \\
\text { responses }\end{array}$ & $\begin{array}{l}\text { Relevant } \\
\text { comments }\end{array}$ & $\begin{array}{l}\text { Independent } \\
\text { Statements }\end{array}$ \\
\hline $\begin{array}{l}\text { Interaction in } \\
\text { collaborative } \\
\text { e-learning }\end{array}$ & 3 & 10 & 4 & 1 & 2 \\
\hline $\begin{array}{l}\text { Research into } \\
\text { e-learning }\end{array}$ & 1 & 6 & 1 & 3 & 2 \\
\hline $\begin{array}{l}\text { Definitions of } \\
\text { e-learning }\end{array}$ & 2 & 9 & 1 & - & 6 \\
\hline $\begin{array}{l}\text { Formal educa- } \\
\text { tion versus train- } \\
\text { ing }\end{array}$ & 4 & 7 & 1 & 1 & 2 \\
\hline e-Learning 2.0 & 6 & 7 & 3 & 2 & 4 \\
\hline $\begin{array}{l}\text { Research to ob- } \\
\text { tain articles }\end{array}$ & 2 & 4 & - & 1 & 3 \\
\hline $\begin{array}{l}\text { Demand-driven } \\
\text { e-Learning } \\
\text { Model and WBL }\end{array}$ & 3 & 4 & 1 & - & - \\
\hline $\begin{array}{l}\text { Amazon's Kin- } \\
\text { dle }\end{array}$ & 4 & 6 & - & 1 & 6 \\
\hline Row total & 25 & 53 & 11 & 9 & 25 \\
\hline \multicolumn{5}{|c|}{ Total number of points/responses in the eight topics analysed } & 123 \\
\hline
\end{tabular}

Within the eight topics, 123 points or responses were made. Some postings were lengthy and included more than one point or response. This figure (123) is indicated in both tables. The number of new points initiated (last column of Table 1) is not the same as the number of new topics initiated, since new points can be made within a topic. The number of participants who actually initiated new topics is 6 , while the number who initiated new points is 9 who, intotal, made 14 new points (Table 1). Ten of the contributions in the 'Independent statements' column (last column, Table 2) related the topic to relevant experiences in the workplace or other real-world situations. Some who worked directly or indirectly in education, described application of the theory in their own workplace activities.

Results are influenced by the higher activity levels of certain participants. There is seldom a balanced level of representation across participants in online study groups, due to individual styles of electronic verbosity or digital shyness. Some participants perused the site, but contributed little or no content. This unequal participation is discussed in the text.

As course leader, I did not initiate any of these eight topics, but made twelve responsive contributions. Several of my contributions were phrased as questions to prompt the learners and others were guidance to useful sources. I deliberately avoided serving as an instructor or leader in this student forum. Five contributions were made by the invited guest lecturer, mainly being valuable references to relevant academic sources. 


\section{Students' Reflections}

This section is a qualitative study on themes that were addressed in reflective essays by the students and on patterns that emerged from the essays and the online interaction.

\section{Themes and Patterns from Students' Essays}

In the second assignment of ELRN400, there was a major essay question on practical communication and collaboration. The questions had three options. The first option, Question 1.1, was an in-depth essay on their personal observations and reflections of the Fb study group and discussions. It was a requirement to ground the answer in theory by discussing the Group interaction in the light of an article by Ebner (2007) and his definition of E-Learning 2.0. The other two options (1.2 and 1.3) related to aspects of collaborative or individual learning that did not involve the Facebook Group, and were for the use of non-participants.

The discussion following is mainly synthesized from the reflections of students who chose the first option. Outside of the public forum, and in a personal essay-writing space with the course leader, they gave personal opinions. Diverse views were expressed on many of the issues. The researcher analysed the essays manually in a type of grounded theory approach (Glaser \& Strauss, 1967; Strauss \& Corbin, 1990), recording themes and patterns that emerged. Direct extracts are in quotation marks. Saturation was reached at around ten essays with no new themes emerging thereafter, although quotations from several of the subsequent essays are included. Contributions from the discussions are also included. Notable overlaps occurred between the essays and the discussions. This provides triangulation that strengthens the content of this section. There are also contextual comments by the author, where appropriate.

\section{Academic Content of Discussions}

Most students indicated that they had truly learned from others' contributions to the discussion topics, 'Content of high value, well articulated'. Although the tone of the discussions was always polite, there was a range of opinions on some subjects. Some made determined and focused efforts to 'add academic value and initiate discussions'. Sources of contributions ranged: Some discussions started with personal opinions of the writers; others pointed the group to theoretical concepts from the study material; and best, some did independent research and elaborated concepts by sourcing publications beyond study material. It is a standing requirement in ELRN400 to do independent research and report it in assignments. As the course lecturer, I noticed a greater amount of such research in the 2009 cohort and I believe it was due to the public exposure in sharing findings with fellow learners. Students appreciated it when peers shared these websites and articles: 'very relevant'; 'highlighted the worth of collaborative learning'. 'Discussion gave me perspectives that would not be encountered by merely reading the article'; 'Collaboratively, it is possible to digest content and information within a short time'; 'The process of thinking through my own responses helped clarify issues'.

A number mentioned their reservations about contributing. They were awed and 'sometimes intimidated' by the apparent expertise and confidence of others. 'One is insecure to express views, because unsure if what I want to say is relevant or accurate'; 'Being exposed to the refined and polished answers of some participants led to ... academic inferiority'; 'There are those who are outspoken and get really involved in everything '; 'I personally struggled to find something to contribute to the forum.' Another felt under pressure to 'perform' when 'the Prof was watching', while another 'did not even realize that the person she was referring to was the lecturer'. And the most encouraging: 'The brief experience where I shared my views was almost like a turning point. My confidence peaked ... and I am not thinking of quitting any more'. 
Considering others' contributions, several reflected on the validity and authenticity of content. 'How do I know that what a student says is correct?'; 'What is opinion and what is fact?'. 'Discussions ... confuse and illuminate, depending on the quality, e.g. 'I think ...' '. One writer claimed that his posting had been challenged. Another advised more challenges "which would be 'good for academic debate'.

The reservations about contributing are due to intimidation by the perceived superiority of fellow students. Some of these were made by those who are achievers in their own right. Such a comment was made by a participant whose own work had awed peers. Nevertheless, it is acknowledged that one's workplace and the work done there, can give a position of strength.

\section{The Technological World of Social Networking Sites}

In the digital age, approaches to the electronic content vary. Young net-generation students are immersed in virtuality and happy there, 'My generation is obsessed with technology and always interconnected. We are part of the 'mobile-connected-internet-global-village generation ... with Web 2.0 fever ... in search of the latest and greatest techno-craze'. Facebook was their comfort zone - one student was engaged in a development project to extend some of the Facebook functionality. For them, its 'well structured, predefined areas' were ideal for ELRN400's practical interaction. They were 'in charge of their participation' and initiated several discussion topics.

Those who are less young had to overcome barriers. Most of the older students had joined $\mathrm{Fb}$ specifically for the e-learning Group. They came with academic perceptions, different from the perception of younger students who were long-term $\mathrm{Fb}$ users. At least six joined Facebook for the first time and encountered snags in registering or logging in. Attitudes to digital media and hard copies also varied: 'I prefer to print postings and read the serious content later'. Another negative factor is the 'lack of security and fear of intruders'. (Note: It does not appear that the learner who mentioned security and intruders, knew that our Group had an intruder - see the subsection, Privacy, in the previous section.

Society is moving toward electronic textual communication by text. Many prefer text messages on a mobile phone or an e-mail to a phone call. Some students are more at ease with an online forum to study content than with a contact study group, for example, 'The ability to recall online discussions ... is superior ... to searching through paper-based discussions ... or recalling verbal conversations'. This mode could serve well for special-needs, such as autistic learners who battle with face-to-face communication.

\section{Relationship to Real World}

IT practitioners, system developers and educational professionals shared their experiences. Some of the concepts taught in the course were already being applied in their workplaces, which led to comparisons of the degree of success. In her assignment, a student addressed workplace forums and compared those in others' workplace to the one in hers, which was proceeding smoothly and effectively. These real-world encounters added authenticity, but the descriptions daunted others who were not employed in such milieus. Although to the administrators, the heterogeneity was enriching and all students were viewed with equity and equality, some students felt inferior.

\section{Role of Administrators and Course Leader}

The administrators were the official site administrator and the course leader (also referred to as the lecturer). Their role was responsive rather than taking the initiative. Some students would have liked tighter control, for example, 'The lecturer should post a weekly question', but as was stated in the tutorial matter, 'it is ... YOUR forum, your study group. Academics will take a back seat'. However, a salient issue is the accuracy of student contributions. Some participants were 
concerned about being misled if fellow students made incorrect statements. They felt that the lecturer should monitor content strictly, using standards and quality assurance to test contributions for relevance and value in supporting learning. 'She should implement verification' and avoid any possibility of students being misled by 'inaccurate opinions'. It was suggested that the administrators should control, edit and delete. Regarding possible inaccuracies, I avoided passing judgement in the role of sage on the stage and aimed instead to be a sage on the side, discerningly intervening, guiding and prompting when appropriate and reminding students (after misleading or vague posts) that the correct information was in the study material. Although some contributions were weak, they were obviously so, of the 'I think...' genre, and not likely to mislead. There was no heretical, yet convincing, content that posed a serious risk. I believe that a culture of criticising 'weak' postings or removing content that did not represent classic theory could demoralize contributors and run counter to the constructivist ethos of learners interpreting material. This was explicitly not a controlled, behaviourist environment, so it was a deliberate decision not to judge contributions and to let students drive the initial round of discussions, which generated fifteen student-initiative topics as well as 'Introduce Yourself and the Wall'. The two topics in the second round of discussions (not addressed in this paper) were set by the lecturer for end-of-year revision. As already stated, eight topics are discussed in this paper.

Students reflected openly on misgivings. Several wrote about feelings of insecurity and lack of confidence in making postings. This confirmed that 'forced removals' would have intimidated them even more. Two complained about the books advertised by the intruder. They bothered me too, but being a newbie myself to $\mathrm{Fb}$ groups, I had assumed initially that the adverts were a $\mathrm{Fb}$ posting. In due course they disappeared. Regarding removals and deletions, I did, however, remove the intruder. In addition, I deleted one contribution deliberately and another accidentally. One student retrospectively deleted his/her own contributions.

The forum was 'well managed' according to a member who stated that 'lecturer took a back seat, but stepped in from time to time to guide'. Another perceptive remark: 'The encouragement afforded by the professor who is merely facilitating the dialogue, is a new paradigm of teacherlearner interaction... which contributes to an enriched and motivational learning experience'. To affirm this, there is a clear and explicit warning in the tutorial matter that accuracy and rigour come from the study material and other accredited literature, and not from opinions.

\section{Integration of Social and Academic Use}

The longtime Fb fans used their visits for 'social and educational purposes'. 'Facebook is both entertaining and a useful learning tool'. Three acknowledged experiencing distractions on their academic visits: 'Friends finding you online want to interact, whereas you are there for academic reasons.' Others who joined to become part of the Group were distracted by 'family and friends who want to be your friend!'. Two decided to use Fb for academic purposes only.

A proponent of using $\mathrm{Fb}$ for both social and academic purposes pointed out that learning via $\mathrm{Fb}$ is cost-effective, since it uses technology and skills that students already possess. There were queries about ways of uploading articles onto $\mathrm{Fb}$ and requests for study material to be copied onto our Group site. My response is an unequivocal 'No, we will not use it for providing course materials'. The university has official channels for this. Any use of Facebook should be optional and supplementary and, in our context of global distance learning with an African emphasis, Facebook cannot be an official repository. Membership cannot be mandatory and there should be no disadvantage to students who did not join. 


\section{Interaction}

There was an informal and relaxed style. Participants felt free to 'talk' and express in ways themselves in ways in which they felt comfortable. Light hearted banter and humour occurred alongside serious and deep contributions. Many agreed that they had fun on the Group.

Remarks about expectations of feedback on their postings were particularly notable. I had not realized how much it meant to students to know how others perceived their individual contributions. Several students made similar points; they were 'disappointed, even demoralized' when there was not a response to their post on a topic. There was a complaint about 'lack of immediacy' of responses. 'The caveat to this feeling of euphoria (after making a posting) was that only one student has commented on my views'. By contrast, some positive experiences: it was 'heartening when others agreed with me'; 'There is more time to think than when responding verbally'.

For those who viewed the site to read and learn, it was disappointing when, at times, there were no new comments. One member subscribed to a $\mathrm{Fb}$ service for notifying him of entries on particular topics. On the opposite end of the scale, a student recorded her surprise that 'regulars' like to comment on everything.

The concerns about responses express a valid viewpoint, indicating self-consciousness about contributions. An insensitive response could easily demotivate a newbie. I did not note any demoralizing occurrences in our group, but the point is taken. The lack of responses mentioned by several, tends to occur when the next contributor comes with a pre-prepared comment. In this way two or three new points are made consecutively and the conversation moves on without adequately considering previous contributions. The point about 'regulars' who have a great deal to say, is noted. It might contribute to the sense of being intimidated.

\section{Meeting Others}

The new Group members declared their initial presuppositions. One wondered whether an academic group could be 'more than a social networking experience?'. Another who, although he used $\mathrm{Fb}$ to keep contact with school friends and people overseas, acknowledged that he viewed it as 'shallow and insincere'.

Most participants enjoyed the 'virtual presence' and the experience of interacting with the lecturer and fellow students: 'Meeting classmates overcomes isolation'; 'an excellent idea'. The group members are 'friendly, enthusiastic and passionate about the subject'. Students were especially pleased to interact with peers around the world. A comment was made about tapping into the 'collective consciousness of a diverse group of people'. There was a suggestion that electronic contact can eliminate possible prejudices or preconceptions. Some had reservations: 'Good to interact, but I enjoyed meeting fellow students more than I benefited academically'; 'Fulfilling, but I am not accustomed to the medium'.

Several formed alliances (positive alliances, not manipulative Survivor-style alliances) and communicated off-forum. A student invited others to communicate with her, so she could share resources via personal e-mail addresses. Some were grateful, while others had reservations and denied permission.

Seven students explicitly mentioned the contribution of the guest professor and the useful publications he made available to them for their research.

\section{Constructivist Learning Paradigm}

In the discussions and the essays, several students termed the approach 'constructivist learning', where they were proactive and empowered, while the teacher was a facilitator and guide, not an 
instructor. For real-world authenticity, some of them applied their new learning to their workplace activities, either changing the way they taught (if they were educators) or describing practices in their workplace and discussing to what extent they did or did not empower the employees. Constructivism and empowerment were not easy for learners accustomed to traditional instructivist teaching, structured systems, and fixed curricula. In particular, certain less-young Group members experienced some discomfort with the learner-controlled approach. The author acknowledges that constructivism and the associated e-Learning 2.0 (Ebner, 2007) are not suitable for all learners, all content, all contexts, and all situations, but believes that such exposure is essential for postgraduate students taking e-learning courses.

Collaborative work is closely associated with social constructivism. Students felt that social networking groups have potential for facilitating and hosting collaborative work. Four suggested collaboratively constructing input on a theme. Facebook does not have facilities for editing others' contributions, so such a project would have to be done with supplementary technology

\section{General Perceptions of the Facebook Forum: Negative and Positive}

Students were honest in their answers and criticisms, e.g. 'Facebook is not for me'. There were clear perceptions of $\mathrm{Fb}$ as a social tool for youth. Some changed this stance as the interaction progressed, but others did not. One viewed the Group as a 'novel approach', an 'experiment in which the idea could germinate', and another wondered whether 'undergraduates would find it more fun'. Another struggled with the time to view the site 'daily' (which had not been advocated). Some of the more skeptical felt that 'Much of the (first round of discussions) was purely to enable completion of the assignment, rather than to gain insights'. (I re-emphasise that the assignment could be completed without doing the Facebook option and that those who did Question 1.1, did so by choice.)

From the opposite viewpoint, keen proponents were convinced of its value and concerned that not all students had joined. They wanted membership of the Group to be compulsory. This issue of non-mandatory use has twice been addressed in earlier sections of the paper. A valid suggestion by an enthusiast was, 'The group should have been facilitated from the time of registration. Then there would have been more members'. In fact, the initial study material had informed students that there would be a discussion forum and some interaction on Facebook. The actual Group and Discussion Forum were created early in the academic year, but there was a lag-time of about six weeks while the associated tutorial letter with instructions was produced, printed and mailed. Although there is an official university web site for each module on which tutorial material is uploaded for immediate accessibility, many students do not use it and did not know details about the group until they received them in the conventional mail. Whether it is an official site or whether it is a Facebook study group, regular visits to electronic sites are not yet part of the general culture in our university. This is an issue that should, and probably will, change. Students continued joining throughout the year and newbies joined in the late-year discussions.

Some of the non-participating members expressly preferred to be observers, perhaps due to lack of confidence. Others did not understand how to join the discussion on various topics. This is another lesson for the facilitators: we should have supplemented the join-up instructions with join-the-discussions instructions. Early in 2009, it was easy to miss the unobtrusive clickable menu item $<$ Discussions $>$. Later in 2009, Facebook changed its default $<$ Groups $>$ home page to accentuate the menu items that represented discussions. This would indicate that it was not only in our Group that members missed the relevant menu items. With hindsight, we should have explained in a tutorial letter how to participate in discussion topics and how to write on the Wall. At least two members expected that an invitation to join discussions would automatically come to their e-mail account. 
Just as membership of the Group is optional, so too is participation. Learners are free to operate according to their personal learning styles. One acknowledged that she logs in daily to see new contributions and the latest topics but, as an introvert, she only made one short comment. She is so enthusiastic about the potential of Facebook groups that she would like to see similar educational groups for school children.

For several participants, their initial perceptions changed: 'A great exercise and very worthwhile, even though Facebook is not my favourite thing'. One outlined impressions of various other forums, which he/she had used '...to pose questions, to seek and provide answers, but (I) dislike the dull, basic, standard and uncreative presentation'. That student appreciated the academic use of $\mathrm{Fb}$, as a 'single point of entry', which many of students already use for 'working smartly'.

\section{E-Learning 1.0 and 2.0}

The essay question required discussion of the themes of Ebner (2007), relating Web1.0 and 2.0 to e-Learning 1.0 and 2.0 respectively. A student explained that in E-Learning 1.0, teachers create content (e.g. multi-media, tutorials and simulations) with which learners can actively engage, but in E-Learning 2.0, learners contribute the content themselves and engage actively in a more constructive way. In another student's terms, Web 2.0 and e-Learning 2.0 are social phenomena rather than electronic ones.

Students initially struggled to understand the Ebner article, but one pointed out that reading the textbook and tutorial material as a foundation, fostered the necessary comprehension. This statement is exactly the point I made in several of my postings, when I referred students to the academic content. Postgraduate modules are grounded in theory and students should study the concepts thoroughly and holistically; they should not just cursorily look for answers to particular questions. A few students referred to Ebner's attitude to social networking for learning and the major associated paradigm shift embodied in his definition:

\section{e-Learning 2.0 $=$ F(e-Learning 1.0, Web 2.0, human factors).}

Participants noted his call for educators to combine what he terms 'openness, socialness and teachness'. A participant described his own 'Eureka moment' when he grasped the 'human factor' concept and realized that in e-Learning 2.0, anyone can author content for the Web. He personalized this to his own initiation of topics and exclaimed, 'This Facebook group is a prime example of what e-Learning 2.0 can be'.

\section{Conclusions}

We re-visit the research questions and answer them concisely, based on the findings of this study. and noting lessons to be learned by educators. Points that relate to the three questions occur throughout the paper, but major factors are re-iterated here:

\section{What Was the Nature of Discussion Content?}

Tables 1 and 2 show that of the eight topics selected for analysis in this study, the first six relate to the academic content of the module ELRN400. Independent sourcing of appropriate publications is a requirement in the module, hence the topic on research to obtain articles. Discussions centred around aspects of the module that are less clear-cut or that involved additional reading. No topic related simplistically to direct bookwork or merely stated the obvious. Much of the content revealed insightful contributions from participants who were acutely perceptive. Very few of the postings could be viewed as platitudes. A major section of ELRN400 has a human-computer interface (HCI) perspective and includes the study of e-learning applications. In this regard, stu- 
dents initiated topics on usability evaluation of e-learning, which is a study in its own right and beyond the scope of this paper.

The other two topics, demand-driven learning and Amazon's Kindle respectively, represent practical applications of theory, as students applied course concepts to contemporary phenomena and made insightful contributions. In other postings, members applied course concepts to real-world experiences, such as those in their workplaces. Some described how they changed their practices in the light of their new learning.

A few topics were outside the direct scope of ELRN400, e.g. technical issues, general queries, and matters about another module. These discussions were brief and had very few contributions.

It is a requirement of ERLN400 for students to do independent research. The study material provides them with guidelines on how to access accredited and reputable sources, and the first assignment has a question asking them to list relevant references. The assignment was generally well done, but in their initial enthusiasm to communicate rapidly on Facebook, students tended to sideline the academic searches and used popular sources, Wiki's, and keyword searches to access information. They shared these findings with the Group,and I responded by referring them again to the data bases provided by our university library and to scholar.google. It was encouraging to note movement towards a more rigorous approach.

Several members chose to maintain privacy and anonymity. A few used pseudonyms and some preferred not to upload face photographs.

\section{What Were Students' Reflections on the Experience?}

Initial perceptions were of two kinds: At least four members were aged over fifty. They had joined $\mathrm{Fb}$ specifically for the group and did not find the process easy or intuitive. Most members were in the mid-twenties to thirties - keen 'techies', immersed in technology and always interconnected. Facebook is an integral and ubiquitous part of their lifestyle and to them it came naturally to use it in their studies as well.

Regardless of their perceptions of Facebook itself, participants really appreciated interaction with fellow learners, 'meeting classmates' as one termed it, in contrast to the isolation that usually accompanies distance learning. The contact with a heterogeneous group of students from around the globe, provided multiple and enriching perspectives

There were varying perceptions on the role of the course leader. Conservative students would have liked a more controlled, instructor-led forum, rather than the constructivist, learner-centred approach that many students identified and appreciated, and mentioned in the reflective essays. A valid concern was the fear of being misled by inaccurate information. Several students requested that content should be monitored by applying quality control and verification to each posting. Erroneous material should be deleted. My approach was to avoid passing judgement in the role of sage on the stage, aiming rather to be a sage on the side, intervening and prompting where appropriate and reminding students (after misleading or vague posts) that accurate information could be obtained in the study material and from accredited sources. In fact, there were no heretical or risky uploads and I deleted only one posting.

Constructivism avoids treating learners as passive receptacles and aims to support them in personally making discerning interpretations. Learner-empowerment is part of the experience, and some students commented on this, one referring to it as 'a new paradigm of teacher-learner interaction' which enriches the learning.

Several expressed reservations and feelings of inadequacy about posting contributions. They were daunted by the apparent expertise and confidence of others despite, in many cases, their own 
personal strengths. When they uploaded comments, they waited eagerly for others' responses to their input. This confirms that criticism of weak postings or removal of imperfect content could demoralize and discourage contributors, and should be handled with great sensitivity.

\section{Can Active Participation in an Academic Facebook Group Support Learning?}

The general reflections and the particular subsection on 'Academic content' indicate that study group members did indeed learn from involvement in the online discussion forum on Facebook. In particular, they benefited by researching beyond the study material and by making personal contributions. By interactively authoring Web content, they had not only experienced subjectmatter learning, but had also been exposed to Ebner's (2007) e-Learning 2.0.

\section{Acknowledgements}

Dr Filstea Naude, our subject librarian, for her assistance in sourcing publications towards the literature study.

Ms Annah Mmacaha, a research assistant who helped in technical aspects related to the literature study.

Mr Marco Pretorius for assistance, support and enthusiastic commitment in setting up and coadministering the Group environment. The author and Marco are committed to collaborative research on various aspects of use of Facebook and its usability.

Students from the ELRN400 cohort of 2009 who joined the Study Group and participated in discussions.

\section{References}

Anderson, S., Folkestad, J., \& Al Doubi, S. (2009). Faculty use of social networking: Ethical issues considered. Proceedings of E-Learn 2009, World Conference on E-Learning in Corporate, Government, Healthcare and Higher Education: 2101-2103.

Bos, N., Karahalios, K., Musgrove-Chavez, M., Poole, E. S., Thomas, J. C. \& Yardi, S. (2009). Research ethics in the Facebook Era: Privacy, anonymity, and oversight. Proceedings of CHI 2009 Special Interest Groups: 2768-2770.

Cloete, S., De Villiers, C. \& Roodt, S. (2009). Facebook as an academic tool for ICT lectures. Proceedings of SACLA 2009: 16-22. ACM International Conference Proceedings Series.

De Wever, B., Schellens, T., Valcke, M. \& Van Keer, H. (2006). Content analysis schemes to analyze transcripts of online asynchronous discussion groups: A review. Computers \& Education, 46, 6-28.

de Villiers, R. (2005). e-Learning artefacts: Are they based on learning theory? Alternation, 12.1b, 345371.

Ebner, M. (2007). E-Learning $2.0=$ e-Learning 1.0 + Web 2.0. Proceedings of the Second International Conference on Availability, Reliability and Security (ARES'07): 1235-1239.

Glaser, B. G., \& Strauss, A. L. (1967). The discovery of grounded theory. Chicago: Aldine.

Henri, F. (1992). Computer conferencing and content analyis. In A.R. Kaye (Ed.), Collaborative learning through computer conferencing. The Najadan papers (pp. 117-136). London: Springer Verlag.

Lampe, C., Ellison, B. N. \& Steinfield, C. (2008). Changes in use and perception of Facebook. Proceedings of CSCW'08: 721-730, San Diego, California, USA. 
Lewis, K., Kaufman, J., Gonzalez, M., Wimmer, A., \& Christakis, N. (2008). Tastes, ties, and time: A new social network dataset using Facebook.com. Social Networks, 30, 330-342.

Madge, C., Meek, J., Wellens, J., \& Hooley T. (2009). Facebook, social integration and informal learning at university: 'It is more for socializing and talking to friends about work than for actually doing work?' Learning, Media and Technology, 34(2), 141-155.

Mazer, J. P., Murphy, R. E., \& Simonds, C. J. (2009). The effects of teacher self-disclosure via Facebook on teacher credibility. Learning, Media and Technology, 34(2), 175-183.

Mouton, J. (2001). How to succeed in your Master's and Doctoral Studies: A South African guide and resource book. Pretoria: Van Schaik Publishers.

Pempek, T. A., Yermolayeva, Y. A., \& Calvert S. L. (2009). College students' social networking experiences on Facebook. Journal of Applied Developmental Psychology, 30, 227-238.

Selwyn, N. (2009). Faceworking: Exploring students' education-related use of Facebook. Learning, Media and Technology, 34(2), 157-174.

Strauss, A. L., \& Corbin, J. (1990). Basics of qualitative research: Grounded theory procedures and techniques. Newbury Park, CA: Sage.

\section{Biography:}

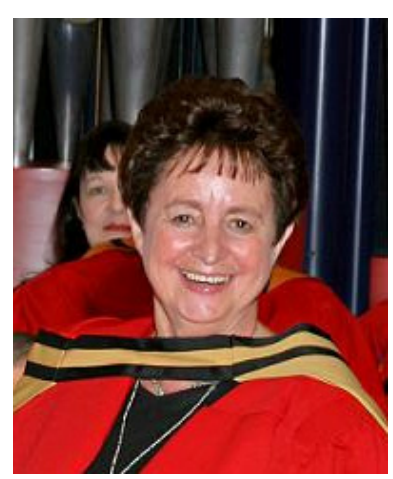

Ruth de Villiers is a professor in the School of Computing at the University of South Africa (UNISA), one of the world's mega-universities. UNISA is a distance-teaching institution, which emphasizes the role of research into open distance learning and educational technology.

Ruth has a PhD and also holds masters degrees in the domains of Information Systems and Computer-integrated Education, respectively. For more than twenty five years, she has taught Computer Science and Informatics. Her major current research interests and teaching areas are Human-Computer Interaction and e-Learning. She has combined these areas by undertaking research and development in the usability and usability evaluation of a broad variety of e-learning applications and environments, including systems targeting users across the Digital Divide. She has also published in the focus area of meta-research, involving work on various research designs and methodologies. Ruth supervises masters and doctoral students in the fields mentioned above. 